\title{
Articaine: a review of the literature
}

\author{
K. E. Yapp, ${ }^{1}$ M. S. Hopcraft ${ }^{2}$ and P. Parashos ${ }^{3}$
}

IN BRIEF

- Provides a comprehensive review on articaine use in dentistry.

- Compares other local anaesthetics in different settings.

- Outlines the use of articaine in children.

- Discusses the controversy regarding neurotoxicity and highlights the quality of the available evidence.

\author{
VERIFIABLE CPD PAPER
}

\begin{abstract}
Articaine is one of the most recent local anaesthetic drugs made available to dentists worldwide. Anecdotal reports advocate its superiority over other common local anaesthetic agents and controversy exists concerning its clinical safety. This article reviews the current literature on articaine use in dentistry specifically addressing the issues of efficacy and safety.
\end{abstract}

\section{INTRODUCTION}

Pain control in clinical dentistry is mainly achieved using local anaesthetic (LA) drugs. Articaine was originally synthesised as carticaine in 1969 and entered clinical practice in Germany in $1976 .{ }^{1}$ The name was changed in 1984, the year it was released in Canada. ${ }^{2}$ It then entered the United Kingdom in $1998,{ }^{1}$ the United States in $2000^{3}$ and Australia in 2005. ${ }^{4}$ Currently, articaine is available as a $4 \%$ solution containing 1:100, 000 or 1:200, 000 adrenaline.

\section{PHARMACOLOGY}

Articaine (4-methyl-3-[2-(propylamino)propionamido]-2-thiophene-carboxylic acid, methyl ester hydrochloride) is a unique amide LA in that it contains a thiophene, instead of a benzene, ring (Fig. 1). The thiophene ring allows greater lipid solubility and potency as a greater portion of an administered dose can enter neurons. ${ }^{5}$ It is the only amide anaesthetic containing an ester group, allowing hydrolysation in unspecific blood esterases. ${ }^{6}$

General Dental Practitioner, Melbourne, Victoria; ${ }^{2}$ Associate Professor, Director of Clinical Education, Melbourne Dental School, The University of Melbourne, Australia; ${ }^{3}$ Associate Professor, Head of Endodontics and Restorative Dentistry, Melbourne Dental School, The University of Melbourne, Australia

*Correspondence to: Associate Professor

Matthew Hopcraft

Email:m.hopcraft@unimelb.edu.au

\section{Refereed Paper}

Accepted 9 December 2010

DOI: $10.1038 /$ sj.bdj.2011.240

${ }^{\circledR}$ British Dental Journal 2011; 210: 323-329

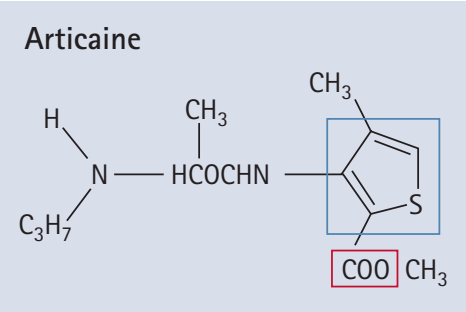

Mepivacaine

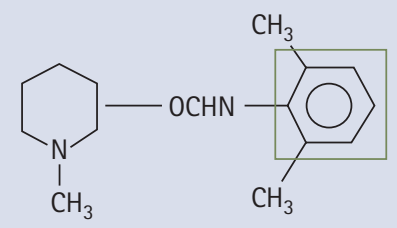

Bupivacaine

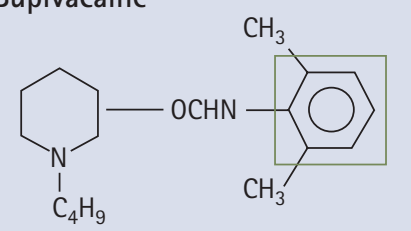

Fig. 1 Structure of amide local anaesthetics

Articaine's amide linkage undergoes biotransformation in the liver, a relatively slow process, however articaine is additionally inactivated by serum esterases, a fast process commencing immediately after injection. ${ }^{6}$ About $90 \%$ of articaine metabolises quickly via hydrolysis in the blood into its inactive metabolite articainic acid, which is excreted by the kidney in the form articainic acid glucuronide. ${ }^{7}$ Its metabolism is age dependent, where clearance and volume of distribution decreases with increasing age. ${ }^{8}$ The elimination

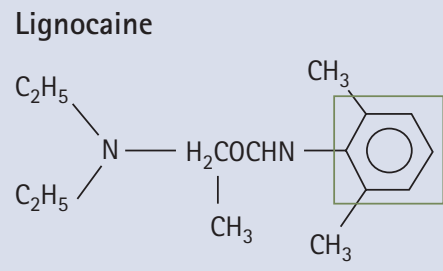

Prilocaine

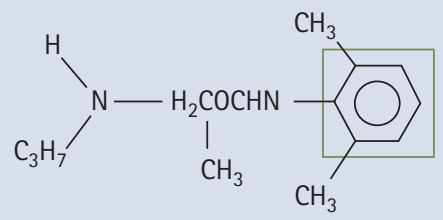

_ thiophene ring

_ ester link

benzene ring

Adapted from Handbook of local anesthesia ${ }^{2}$ 
to the advantageous relationship between persistence of the local anaesthetic effect and low systemic toxicity. ${ }^{10}$ The increased duration of the local anaesthetic effect may also be related to the high degree of protein binding, where the increased tendency for articaine to attach securely to the protein receptor site may provide a longer duration of clinical activity. ${ }^{11}$ There is no correlation between the serum concentration and local anaesthetic effect of articaine. ${ }^{6}$

\section{EFFICACY}

Articaine can provide clinically effective pain relief for most dental procedures similar to other commercially available local anaesthetics ${ }^{1}$ and has also been reported to provide sufficient anaesthesia for reduction of complex orbitozygomatic fractures under local anaesthesia. ${ }^{12}$ Anaesthetic concentration has no significant effect on clinical efficacy. When $2 \%$ and 4\% articaine with 1:200,000 adrenaline (2\% A200 and 4\% A200 respectively) were used for extractions of maxillary and mandibular teeth, 4\% A200 did not have a superior anaesthetic effect. ${ }^{13,14}$ However an in vitro study showed that $2 \%$ and $4 \%$ articaine more effectively depressed the compound action potential of all $\mathrm{A}$ fibres in rat sensory nerves than $2 \%$ and 4\% lignocaine and 3\% mepivacaine could and $4 \%$ articaine was more effective than $2 \%$ articaine. ${ }^{15}$ Currently it is not known why articaine is only manufactured in a $4 \%$ solution given that the limited data show no clinical advantage over a $2 \%$ preparation. One reason may be that the lower systemic toxicity of articaine allows it to be used in a concentration higher than other amide LAs. ${ }^{6}$ Vasoconstrictor concentration has had little effect on certain clinical properties. In mandibular first premolars anaesthetised with an inferior alveolar nerve block (IANB), no significant differences in the duration of or ability to induce pulp and soft tissue anaesthesia, as determined by electric pulp tester (EPT) readings or patient reported lip numbness, were observed between 4\% articaine with 1:100,000 adrenaline (4\% A100) and 4\% A200. ${ }^{16}$ Similarly, no significant differences were found in the level of pulpal anaesthesia between 4\% A100 and 4\% A200 for maxillary infiltration and IANB anaesthesia. ${ }^{17}$ Hersh et al. found that plasma concentration curves were similar in patients receiving both $4 \%$ A100 and 4\% A200 and concluded that 4\% A200 is as safe as $4 \%$ A100. ${ }^{18}$ For patients receiving 4\% A200 and 2\% lignocaine with 1:100,000 adrenaline ( $2 \%$ L100), no significant difference was found between the two solutions in regard to heart rate, systolic and diastolic blood pressure and oxygen saturation. ${ }^{19}$ In the surgical setting, adrenaline concentration in 4\% A100 or 4\% A200 has been shown not to affect the patient's perception of anaesthetic duration, postoperative analgesia or clinical efficacy during the removal of mandibular third molars. ${ }^{20}$ When extracting impacted maxillary third molars, a higher buccal vestibule-palatal diffusion occurred with a greater concentration of adrenaline (4\% A100 compared to 4\% A200) after ten minutes. ${ }^{21}$ In periodontal surgery, both $4 \%$ A100 and 4\% A200 provided similar levels of patient-reported pain control, however, 4\% A100 provided less bleeding and better visualisation of the surgical field. ${ }^{22}$

\section{COMPARISON WITH OTHER ANAESTHETICS}

Clinical trials comparing articaine with other LAs have varied in study design and site of action with most comparisons made with lignocaine, the current standard to which all new local anaesthetics are compared. ${ }^{2}$ Anaesthetic success of sound teeth in healthy volunteers has been defined as the ability to achieve two or more consecutive EPT readings of 80 . An early report by Cowan revealed that while carticaine had satisfactory clinical properties, it also had a variable onset time and poor predictability for profound anaesthesia. ${ }^{23}$ Anaesthesia of maxillary teeth have had varying results; articaine has been shown to have a significantly shorter latency and longer duration of pulpal anaesthesia than lignocaine in posterior teeth ${ }^{24}$ but not in anterior teeth. ${ }^{25,26}$ Articaine also has a significantly higher success rate than lignocaine in the maxillary lateral incisor but not in the maxillary first molar. ${ }^{27}$ No significant differences between prilocaine and articaine were found in onset time and anaesthetic duration $^{28}$ or in the ability of the two LAs to induce pulpal, buccal or palatal tissue anaesthesia in maxillary canines ${ }^{29}$ or second molars. ${ }^{30}$ Trials comparing mandibular buccal infiltrations have found no significant difference in anaesthetic success rate for pulpal, buccal or lingual tissue for mandibular canines ${ }^{29}$ or mandibular second molars ${ }^{30}$ when articaine and prilocaine were used, or when buccal infiltrations were compared to buccal and lingual infiltrations of articaine in mandibular first molars. ${ }^{31}$ Alternatively, articaine buccal infiltrations have had significantly higher anaesthetic success rates than lignocaine in mandibular first molars, ${ }^{32,33}$ mandibular premolars and molars ${ }^{34}$ and in the incisive/mental nerve block for mandibular premolars, canines and lateral incisors. ${ }^{35}$ No significant differences in their ability to achieve pulpal anaesthesia were found between articaine and lignocaine when a periodontal ligament (PDL) infiltration was used in mandibular first molars. ${ }^{36}$ The inferior alveolar nerve block (IANB) is commonly used for employing pulpal anaesthesia of mandibular teeth however its success has been relatively modest, with approximately 15 to $20 \%$ of IANBs providing inadequate anaesthesia. ${ }^{2}$ Articaine and lignocaine had similar success rates when used for administering the IANB. ${ }^{37}$ A supplemental buccal infiltration of articaine adjacent to a mandibular molar after an IANB has been shown to have a significantly higher success rate than lignocaine or a dummy injection in mandibular posterior ${ }^{38}$ and anterior teeth. ${ }^{39}$ Other reports show no significant increase in anaesthetic success of mandibular teeth when lignocaine is used as a supplemental buccal or lingual infiltration ${ }^{40}$ or mylohyoid nerve block after an IANB. ${ }^{41}$ When articaine was used for either an IANB or buccal infiltration, both techniques had similar success rates in providing mandibular first molar pulpal anaesthesia however a buccal infiltration had a faster latency. ${ }^{42}$ After surgical extraction of impacted mandibular third molars, articaine had a longer duration of postoperative anaesthesia and a significantly longer analgesic duration than mepivacaine ${ }^{43}$ and lignocaine. ${ }^{44}$ Articaine also had a significantly shorter latency and duration of soft tissue anaesthesia than bupivacaine but a similar duration of postoperative analgesia. ${ }^{45}$ For maxillary tooth extractions, it has been suggested that a palatal injection may not be necessary when articaine is delivered in a buccal infiltration ${ }^{46-48}$ and that most impacted maxillary third molar extractions with 
articaine can be performed without palatal anaesthesia. ${ }^{21}$ These results corroborate findings by Badcock et $a l .{ }^{49}$ who compared lignocaine and placebo saline palatal infiltrations in the extraction of maxillary third molars and concluded that when lignocaine is used in a buccal infiltration, a palatal injection of local anaesthetic may not be required. However, a clinical and magnetic resonance imaging study evaluating palatal diffusion of articaine in the maxillary first premolar and molar region did not detect the presence of anaesthesia following needle prick stimulation or articaine in the palatal tissues after buccal infiltration. ${ }^{50}$ The current literature reports conflicting results regarding the clinical advantage articaine may have over other LAs. A meta-analysis comparing articaine and lignocaine concluded that articaine is more likely to achieve anaesthetic success than lignocaine in the first molar region..$^{51}$ However, this meta-analysis did not take into account the effect of local inflammation or variability of anaesthetic success with certain LA administration techniques such as the IANB. In summary, there is insufficient evidence indicating articaine's superiority and many studies show that its properties are similar to that of other available local anaesthetics (Table 1).

\section{LOCAL ANAESTHETIC FAILURE}

Many mechanisms for local anaesthetic failure have been discussed elsewhere; ${ }^{52-55}$ it is believed that articaine may provide anaesthetic success when other LAs are unable to provide profound anaesthesia. ${ }^{2}$ Teeth with irreversible pulpitis (IP) are perceived to be more difficult to anaesthetise than those with normal pulps because nerves arising from inflamed tissue have altered resting potentials and decreased excitability thresholds. ${ }^{56,57}$ Studies comparing anaesthetic success of different LAs in teeth with IP have defined success as patients reporting no to mild pain on a Visual Analogue Scale (VAS) pain scale during the endodontic procedure. When used as a supplemental anaesthetic, after lignocaine did not provide profound anaesthesia during endodontic treatment in maxillary teeth, no difference in pain experience was found between articaine and lignocaine..$^{58,59}$ Alternatively, articaine was shown to be superior to lignocaine in maxillary posterior teeth for pain

\section{Table 1 Literature comparing articaine properties in healthy volunteers}

\begin{tabular}{|c|c|c|}
\hline \multirow{2}{*}{ Location of comparison } & \multicolumn{2}{|l|}{ Number of studies } \\
\hline & $\begin{array}{l}\text { Articaine is significantly } \\
\text { more successful* }\end{array}$ & $\begin{array}{l}\text { No significant differences } \\
\text { between anaesthetics }\end{array}$ \\
\hline Maxillary infiltration & Evans G et al., $2008^{27}$ & $\begin{array}{l}\text { Oliveira et al., 2004; Vähätalo } \\
\text { et al., 1993; Evans et al., 2008; } \\
\text { Donaldson et al., 1987; Haas } \\
\text { et al., } 1990 \text { and } 1991^{24,25,27-30}\end{array}$ \\
\hline Mandibular infiltration & $\begin{array}{l}\text { Kanaa et al., 2006; Abdulwahab et } \\
\text { al., 2009; Robertson et al., } 2007^{32-34}\end{array}$ & Haas et al., 1990 and $1991^{29,30}$ \\
\hline Incisive/mental nerve block & Batista da Silva et al., $2010^{35}$ & - \\
\hline $\begin{array}{l}\text { Periodontal ligament } \\
\text { infiltration }\end{array}$ & - & Berlin et al., $2005^{36}$ \\
\hline $\begin{array}{l}\text { Inferior alveolar nerve block } \\
\text { (IANB) }\end{array}$ & - & Mikesell et al., $2005^{37}$ \\
\hline IANB + buccal infiltration & $\begin{array}{l}\text { Haase et al., 2008; Kanaa et al., } \\
2009^{38,39}\end{array}$ & - \\
\hline Total & Seven & Ten \\
\hline
\end{tabular}

Table 2 Articaine in irreversible pulpitis

\begin{tabular}{|c|c|c|}
\hline \multirow{2}{*}{ Location of comparison } & \multicolumn{2}{|l|}{ Number of studies } \\
\hline & $\begin{array}{l}\text { Articaine is significantly } \\
\text { more successful* }\end{array}$ & $\begin{array}{l}\text { No significant differences between } \\
\text { anaesthetics }\end{array}$ \\
\hline Maxillary infiltration & Srinivasan et al., $2009^{60}$ & $\begin{array}{l}\text { Rosenberg et al., 2007; Sherman } \\
\text { et al., } 2008^{58,59}\end{array}$ \\
\hline $\begin{array}{l}\text { Inferior alveolar nerve } \\
\text { block (IANB) }\end{array}$ & - & $\begin{array}{l}\text { Claffey et al., 2004; Tortamano et al., } \\
\text { 2009; Maniglia-Ferreira et al., 2009 }\end{array}$ \\
\hline Gow-Gates Block (GGB) & - & Sherman et al., $2008^{59}$ \\
\hline IANB + buccal infiltration & Aggarwal et al., $2010^{68}$ & Rosenberg et al., $2007^{58}$ \\
\hline Total & Two & Seven \\
\hline
\end{tabular}

control during endodontic procedures. ${ }^{60}$ It may be difficult to achieve profound anaesthesia in mandibular posterior teeth, especially when the IANB technique is implemented. ${ }^{61}$ Articaine has not been shown to be superior to lignocaine or mepivacaine in achieving adequate pain control during endodontic treatment in mandibular posterior teeth with IP when the IANB is administered ${ }^{62-64}$ or when the Gow-Gates Block (GGB) is administered. ${ }^{59}$ When articaine was compared in several techniques for mandibular anaesthesia for endodontic treatment of teeth with IP, the GGB technique had a significantly higher success rate than the IANB, VaziraniAkinosi Block (VAB) and buccal plus lingual infiltrations, ${ }^{65}$ however, no technique or anaesthetic provided any acceptable pain control..$^{62,63,65}$ These results differ to a study which compared IANB, GGB and $\mathrm{VAB}$ with lignocaine in sound mandibular teeth showing no significant difference in efficacy between the three methods. ${ }^{66}$ After a lignocaine IANB, no significant difference in pain control was found between articaine and lignocaine for a supplemental buccal infiltration. ${ }^{58}$ Following a lignocaine IANB and long buccal nerve block (LB) that did not achieve profound anaesthesia in a mandibular posterior tooth during endodontic treatment, a prospective study with no experimental variable found that a supplemental articaine buccal infiltration had a 58\% success rate but did not provide adequate or predictable pulpal anaesthesia. ${ }^{67}$ When buccal and lingual infiltrations supplemental to a lignocaine IANB were compared on mandibular teeth with IP, articaine had a significantly higher 
success rate than lignocaine but both techniques were unable to provide acceptable rates of success. ${ }^{68}$ No significant difference was found between IANB and buccal infiltration and IANB and PDL injection with articaine in the mandibular first molar; both having high success rates. ${ }^{69}$ The articaine IANB and PDL injection success rate (83\%) was higher than lignocaine (56\%) when used in a similar setting. ${ }^{70}$ Articaine in an intraosseous injection (IO) supplemental to IANB and LB in mandibular posterior teeth with IP had a success rate of $86 \%$ when delivered with the Stabident system (Fairfax Dental Inc., Miami, FL, USA), ${ }^{71}$ which were comparable to success rates of lignocaine Stabident injections supplemental to IANB in mandibular posterior teeth with IP of 90 and $91 \% \%^{72,73}$ and with lignocaine X-tip (X-tip Technologies, Lakewood, NJ, USA) IO injections of 82\%. ${ }^{74}$ In general, the evidence indicates little benefit in using articaine for IP (Table 2).

\section{USE IN CHILDREN}

In 3-12-year-old children, serum concentrations of articaine were comparable to those in adults, with maximum concentrations of a $2 \%$ solution significantly lower than that of a $4 \%$ one. ${ }^{75}$ Common adverse articaine reactions in children have been reported to be numbness and soft tissue injuries, with prolonged numbness being the most common, mainly occurring in children younger than seven. ${ }^{76}$ Whilst the manufacturer does not recommend articaine use in children younger than four years of age, ${ }^{77}$ an early retrospective report on 211 children under four years of age gave initial evidence reporting no adverse systemic reactions. ${ }^{78}$ An American survey ${ }^{79}$ reported that $21 \%$ of 373 dentists surveyed had used articaine in the 2-3-year-old group. In mandibular primary molars and canines undergoing operative dentistry, a buccal infiltration of articaine achieved anaesthetic success for all procedures in a study of 50 children aged 4-12 years. ${ }^{80}$ In children 3-6 years of age, no difference in the effectiveness of mandibular infiltration was found between articaine, mepivacaine and prilocaine. ${ }^{81}$ Lignocaine infiltrations in primary molars were effective and reliable for amalgam and stainless steel crown restorations but not for a pulpotomy. ${ }^{82}$ Articaine has been as effective as lignocaine when used in patients aged
4- $12^{83}$ and $5-13 .^{84}$ Articaine IO injections in 4-16-year-old children were able to provide successful anaesthesia for a high proportion of deciduous and permanent teeth, with a significantly higher success rate in maxillary teeth. ${ }^{85}$ The available literature on articaine use in children shows that it is safe and effective for clinical procedures in children of all ages.

\section{SAFETY}

All local anaesthetics have the potential to be unsafe, with adverse effects including symptoms of dizziness, disorientation, tremors, convulsions, seizures, hypotension and cardiac and respiratory depression. ${ }^{6,86,87}$ Articaine is one of the safer local anaesthetics due to its rapid metabolism into an inactive metabolite, decreasing the risk of systemic toxicity and overdose, even after repeated injection. ${ }^{6}$ Early studies on articaine reported no toxic reactions from 100 injections, ${ }^{23}$ in 211 paediatric patients ${ }^{81}$ and a recent study showed a low number of adverse events comparable to that of lignocaine. ${ }^{3}$ Other adverse reactions to articaine have been reported, including hypersensitivity, ${ }^{88}$ ophthalmologic complications, ${ }^{89-92}$ ischaemic skin necrosis ${ }^{93}$ and fever, chills and arthralgia. ${ }^{94}$ Controversy exists regarding articaine safety following non-surgical dental procedures with an IANB, which suggests articaine having a higher incidence of paraesthesia (persistent anaesthesia or an abnormal or unprovoked sensation). These suggestions have been based on data from four retrospective reports ${ }^{95-98}$ and two abstracts. ${ }^{99,100}$ When complete data were available, articaine was the LA most commonly associated with paraesthesia (34-60\%), ${ }^{95-98}$ the majority of cases involved the lingual nerve (71-93\%) $)^{95-98}$ and no nerves in the maxilla were affected. Similar studies before articaine release in the USA also showed the lingual nerve had a similar incidence of involvement (71-83\%) with lignocaine being the most commonly used agent (67\%). ${ }^{101,102} \mathrm{~A}$ later study using data when articaine was widely available in the USA contradicted early results, with lignocaine being the most common LA (35\%), followed by articaine and prilocaine (30\% each). ${ }^{103}$ However, the most recent retrospective study ${ }^{98}$ on voluntary reporting of adverse reactions following LA administration in the USA showed that from the available data, 4\% solutions of articaine and prilocaine were associated with a higher frequency of paraesthesia than LAs of a lower concentration. Of all reports, only one case ${ }^{101}$ was associated with a $\mathrm{GGB}^{104}$ and the remaining with an IANB - the Halstead technique. All reports documenting paraesthesia after IANB only included non surgical procedures ${ }^{95,97,99-103}$ except for one ${ }^{96}$ which included 'one simple dental extraction' and another ${ }^{98}$ in which $64 \%$ of their sample consisted of assumed non-surgical paraesthesia cases as the procedural details were unknown. The methodology of data recruitment needs to be carefully examined. All reports suggestive of articaine having neurotoxic potential ${ }^{95-100}$ involved voluntary reporting or referral to the respective insurance board for paraesthesia assessment. As referral following paraesthesia was not compulsory, the collected data cannot be considered a representative sample. This has the potential for underreporting, which 'almost certainly exists'97 and can change the distribution and incidence of nerves affected and LA agents used. The reasons for reporting or not reporting an adverse outcome is beyond the scope of this paper and is an area that needs further research in order to reduce reporting bias. In addition, some studies did not include complete data and instead made assumptions on the procedures involved. Paraesthesia following non-surgical dental procedures is uncommon and the mechanism of nerve damage is unknown, ${ }^{101}$ however, proposed theories regarding susceptibility of the lingual nerve to damage include: direct needle trauma, intraneural haematoma formation, local anaesthetic toxicity and the fascicular pattern. ${ }^{101,105}$ Incidences of lingual nerve damage caused by mandibular block anaesthesia for non-surgical dental procedures have been reported to be between $0.15 \% 0^{106}$ and $0.54 \%{ }^{107}$ and gross estimations of the incidence of paraesthesia after IANB administration for non surgical procedures range from $1: 26,762$ to $1: 785,000$, with the assumption that half of all LA injections involve IANB injections. ${ }^{95:}$ 97, 101: 102 To date, there is only one report in the literature of maxillary paraesthesia involving articaine, however, it was following an extraction. ${ }^{108}$ Only one report of maxillary non-surgical paraesthesia has been documented, following 
palatal-anterior superior alveolar nerve block with lignocaine and mepivacaine. ${ }^{109}$ From the available literature, it is evident that paraesthesia is an extremely rare occurrence and regardless of the LA used, the majority of non surgical paraesthesia cases affect the lingual nerve after IANB administration. Currently no scientific proof exists for this observation. Other reports have suggested that it is not the anaesthetic agent itself but instead the available concentration..$^{97,98,110}$ This is due to $4 \%$ articaine and prilocaine preparations being reported with increased incidences of paraesthesia, but these claims are unproven. Whilst there may be in vitro animal studies linking increased anaesthetic concentration and neurotoxicity, ${ }^{111}$ it does not explain why the majority of non-surgical paraesthesias after IANB preferentially involve the lingual nerve. No scientific evidence exists supporting the claim that articaine is associated with increased paraesthesia ${ }^{112,113}$ and a clear causal relationship has not been established in the literature between anaesthetic agent and neurological complications, such as paraesthesia. ${ }^{114}$ These statements currently remain true. All studies suggesting articaine having an increased risk of neurotoxicity are retrospective and biased in data recruitment, are not high levels of evidence and hence are not suitable for strong recommendations. ${ }^{115}$ In order to prove claims of increased paraesthesia, the current incidence of paraesthesia associated with other anaesthetics needs to be clearly established and further studies are needed to determine a significant increase in paraesthesia associated with articaine, if any. These reports would need to be randomised controlled trials (RCTs) as they not only will contribute to the highest level of evidence, but their design can maximise control over the environment providing the most convincing causal relationship. ${ }^{116}$ Gaffen and Haas concede that 'it would take an unrealistically large trial or cohort to detect statistically significant differences for an event as rare as nonsurgical paraesthesia' and, in reference to the current data on RCTs using articaine, advocate that 'no conclusions regarding permanent paraesthesia should be made from these particular studies.97 To date there is only one $\mathrm{RCT}^{3}$ comparing articaine with other LAs reporting adverse outcomes. This study compared 4\% A100 and 2\% L100 for simple and complex dental procedures, with respective sample sizes of 882 and 443 and respective incidences of paraesthesia of 1 and less than $1 \%$, and did not offer any suggestion of articaine being associated with an increased risk of paraesthesia. In light of this evidence, along with efficacy studies comparing IANBs of articaine with other LAs in sound teeth ${ }^{37}$ and teeth with IP, ${ }^{62-64}$ the literature shows that there is neither no significant clinical advantage nor significant risk of developing a paraesthesia when using articaine instead of lignocaine for an IANB. Therefore, from the current available literature, there is no scientific evidence demonstrating that articaine as a $4 \%$ solution is neurotoxic or unsafe to use in any aspect of clinical dentistry.

\section{CONCLUSIONS}

Although there may be controversy regarding its safety and advantages in comparison to other local anaesthetics, there is no conclusive evidence demonstrating neurotoxicity or significantly superior anaesthetic properties of articaine for dental procedures. Articaine is a safe and effective local anaesthetic drug to use in all aspects of clinical dentistry for patients of all ages, with properties comparable to other common local anaesthetic agents. Therefore, at this time, the decision to use articaine cannot be based on any convincing evidence of superiority over other LA drugs, rather the choice will be based on the personal preference and experiences of individual clinicians.

None of the authors have any financial or personal interest in any of the products mentioned in this article.

1. Malamed S F, Gagnon S, Leblanc D. Efficacy of articaine: a new amide local anesthetic. J Am Dent Assoc 2000; 131: 635-642.

2. Malamed S F. Handbook of local anesthesia. 5th ed p 71. St Louis: Mosby, 2004

3. Malamed S F, Gagnon S, Leblanc D. Articaine hydrochloride: a study of the safety of a new amide local anesthetic. J Am Dent Assoc 2001; 132: 177-185.

4. Gooding N, Brand manager, Henry Schein Halas Australia, written communication, March 2010.

5. Becker D E, Reed K L. Essentials of local anesthetic pharmacology. Anesth Prog 2006; 53: 98-109.

6. Oertel R, Rahn R, Kirch W. Clinical pharmacokinetics of articaine. Clin Pharmacokinet 1997; 33: 417-425.

7. Vree T B, Gielen M J. Clinical pharmacology and the use of articaine for local and regional anaesthesia. Best Pract Res Clin Anaesthesiol 2005; 19: 293-308.

8. Oertel $R$, Ebert $U$, Rahn $R$, Kirch $W$. The effect of age on pharmacokinetics of the local anesthetic drug articaine. Reg Anesth Pain Med 1999; 24: 524-528.

9. Oertel $R$, Richter $K$, Weile $K$, Gramatté T, Berndt A, Feller K. A simple method for the determination of articaine and its metabolite articainic acid in dentistry: application to a comparison of articaine and lidocaine concentrations in alveolus blood. Methods Find Exp Clin Pharmacol 1993; 15: 541-547.

10. Oertel $R$, Berndt $A$, Kirsch W. Saturable in vitro metabolism of artiaine by serum esterases: Does it contribute to the persistence of the local anesthetic effect? Reg Anesth 1996; 21: 576-581.

11. Tucker G T. Plasma binding and disposition of local anesthetics. Int Anesthesio/ Clin 1975; 13: 33-59.

12. Bissada E, Chacra Z A, Ahmarani C, Poirier J, Rahal A. Orbitozygomatic complex fracture reduction under local anesthesia and light oral sedation. J Oral Maxillofac Surg 2008; 66: 1378-1382.

13. Hintze A, Paessler L. Comparative investigations on the efficacy of articaine 4\% (epinephrine 1:200,000) and articaine $2 \%$ (epinephrine 1:200,000) in local infiltration anaesthesia in dentistry - a randomised double-blind study. Clin Oral Investig 2006; 10: $145-150$.

14. Fritzsche $C$, Pässler L. Ultracain D-S und ultracain 2\%-suprarenin-vergleichende untersuchungen zur lokalanästhesie in der zahnärztlichen chirurgie. Quintessenz 2000; 51: 507-514.

15. Potocvnik I, Tomšic M, Sketelj J, Bajrovic F F. Articaine is more effective than lidocaine or mepivacaine in rat sensory nerve conduction block in vitro. J Dent Res 2006; 85: 162-166.

16. Tófoli $G R$, Ramacciato J $C$, de Oliveira P C, Volpato M C, Groppo F C, Ranali J. Comparison of effectiveness of $4 \%$ articaine associated with $1: 100,000$ or $1: 200,000$ epinephrine in inferior alveolar nerve block. Anesth Prog 2003; 50: 164-168.

17. Moore P A, Boynes S G, Hersh E V et al. The anesthetic efficacy of 4 percent articaine 1:200,000 epinephrine: two controlled clinical trials. J Am Dent Assoc 2006; 137: 1572-1581.

18. Hersh E V, Giannakopoulos H, Levin L M et al. The pharmacokinetics and cardiovascular effects of high-dose articaine with 1:100,000 and 1:200,000 epinephrine. J Am Dent Assoc 2006; 137: 1562-1571.

19. Elad S, Admon D, Kedmi M et al. The cardiovascular effect of local anesthesia with articaine plus $1: 200,000$ adrenalin versus lidocaine plus 1:100,000 adrenalin in medically compromised cardiac patients: a prospective, randomized, double blinded study. Oral Surg Oral Med Oral Pathol Oral Radiol Endod 2008; 105: 725-730.

20. Santos C F, Modena K C, Giglio F P et al. Epinephrine concentration $(1: 100,000$ or $1: 200,000)$ does not affect the clinical efficacy of $4 \%$ articaine for lower third molar removal: a double-blind, randomized, crossover study. J Oral Maxillofac Surg 2007; 65: 2445-2452

21. Lima-Júnior J L, Dias-Ribeiro E, de Araújo T N et al. Evaluation of the buccal vestibule-palatal diffusion of $4 \%$ articaine hydrochloride in impacted maxillary third molar extractions. Med Oral Patol Oral Cir Bucal 2009; 14: E129-132.

22. Moore P A, Doll B, Delie R A et al. Hemostatic and anesthetic efficacy of $4 \%$ articaine $\mathrm{HCl}$ with $1: 200,000$ epinephrine and 4\% articaine $\mathrm{HCl}$ with 1:100,000 epinephrine when administered intraorally for periodontal surgery. J Periodontol 2007; 78: 247-253.

23. Cowan A. Clinical assessment of a new local anesthetic agent-carticaine. Oral Surg Oral Med Oral Pathol 1977; 43: 174-180.

24. Costa C G, Tortamano I P, Rocha R G, Francischone C E, Tortamano N. Onset and duration periods of articaine and lidocaine on maxillary infiltration. Quintessence Int 2005; 36: 197-201.

25. Oliveira P C, Volpato M C, Ramacciato J C, Ranali $J$. Articaine and lignocaine efficiency in infiltration anaesthesia: a pilot study. Br Dent J 2004; 197: 45-46.

26. Vähätalo K, Antila H, Lehtinen R. Articaine and lidocaine for maxillary infiltration anesthesia. Anesth Prog 1993; 40: 114-116.

27. Evans G, Nusstein J, Drum M, Reader A, Beck M. A prospective, randomized, double-blind comparison of articaine and lidocaine for maxillary infiltrations. J Endod 2008; 34: 389-393.

28. Donaldson D, James-Perdok L, Craig B J, Derkson 
G D, Richardson A S. A comparison of Ultracaine DS (Articaine $\mathrm{HCl}$ ) and Citanest forte (Prilocaine $\mathrm{HCl}$ ) in maxillary infiltration and mandibular nerve block. J Can Dent Assoc 1987; 53: 38-42.

29. Haas D A, Harper D G, Saso M A, Young E R. Comparison of articaine and prilocaine anesthesia by infiltration in maxillary and mandibular arches. Anesth Prog 1990; 37: 230-237.

30. Haas D A, Harper D G, Saso M A, Young E R. Lack of differential effect by Ultracaine (articaine) and Citanest (prilocaine) in infiltration anaesthesia. J Can Dent Assoc 1991; 57: 217-223.

31. Corbett I P, Kanaa M D, Whitworth J M, Meechan $J G$. Articaine infiltration for anesthesia of mandibular first molars. J Endod 2008; 34: 514-518.

32. Kanaa M D, Whitworth J M, Corbett I P, Meechan $J \mathrm{G}$. Articaine and lidocaine mandibular buccal infiltration anesthesia: a prospective randomized double-blind cross-over study. J Endod 2006; 32: 296-298.

33. Abdulwahab M, Boynes S, Moore P et al. The efficacy of six local anesthetic formulations used for posterior mandibular buccal infiltration anesthesia. J Am Dent Assoc 2009; 140: 1018-1024.

34. Robertson D, Nusstein J, Reader A, Beck M, McCartney $M$. The anesthetic efficacy of articaine in buccal infiltration of mandibular posterior teeth. J Am Dent Assoc 2007; 138: 1104-1112.

35. Batista da Silva C, Aranha Berto L, Cristina Volpato $M$ et al. Anesthetic efficacy of articaine and lidocaine for incisive/mental nerve block. J Endod 2010; 36: 438-441.

36. Berlin J, Nusstein J, Reader A, Beck M, Weaver J. Efficacy of articaine and lidocaine in a primary intraligamentary injection administered with computer-controlled local anesthetic delivery system. Oral Surg Oral Med Oral Pathol Oral Radiol Endod 2005: 99: 361-366.

37. Mikesell P, Nusstein J, Reader A, Beck M, Weaver J. A comparison of articaine and lidocaine for inferior alveolar nerve blocks. J Endod 2005; 31: 265-270.

38. Haase A, Reader A, Nusstein J, Beck M, Drum M. Comparing anesthetic efficacy of articaine versus lidocaine as a supplemental buccal infiltration of the mandibular first molar after an inferior alveolar nerve block. J Am Dent Assoc 2008; 139: $1228-1235$

39. Kanaa M D, Whitworth J M, Corbett I P, Meechan $J$ G. Articaine buccal infiltration enhances the effectiveness of lidocaine inferior alveolar nerve block. Int Endod J 2009; 42: 238-246.

40. Foster W, Drum M, Reader A, Beck M. Anesthetic efficacy of buccal and lingual infiltrations of lidocaine following an inferior alveolar nerve block in mandibular posterior teeth. Anesth Prog 2007; 54: 163-169.

41. Clark S, Reader A, Beck M, Meyers W J. Anesthetic efficacy of the mylohyoid nerve block and combination inferior alveolar nerve block mylohyoid nerve block. Oral Surg Oral Med Oral Pathol Oral Radiol Endod 1999; 87: 557-563.

42. Jung I Y Kim J H, Kim E S, Lee CY, Lee S J. An evaluation of buccal infiltrations and inferior alveolar nerve blocks in pulpal anesthesia for mandibular first molars. J Endod 2008; 34: 11-13.

43. Colombini B L, Modena K C, Calvo A M et al. Articaine and mepivacaine efficacy in postoperative analgesia for lower third molar removal: a double-blind, randomized, crossover study. Oral Surg Oral Med Oral Pathol Oral Radiol Endod 2006; 102: 169-174.

44. Sierra-Rebolledo A, Delgado-Molina E, BeriniAytés L, Gay-Escoda C. Comparative study of the anesthetic efficacy of $4 \%$ articaine versus $2 \%$ lidocaine in inferior alveolar nerve block during surgical extraction of impacted lower third molars. Med Oral Patol Oral Cir Bucal 2007; 12: E139-E144.

45. Gregorio LV, Giglio F P, Sakai V T et al. A comparison of the clinical anesthetic efficacy of $4 \%$ articaine and $0.5 \%$ bupivacaine (both with 1:200,000 epinephrine) for lower third molar removal. Oral Surg Oral Med Oral Pathol Oral Radiol Endod 2008; 106: 19-28.

46. Uckan S, Dayangac E, Araz K. Is permanent maxillary tooth removal without palatal injection possible? Oral Surg Oral Med Oral Pathol Oral Radio Endod 2006; 102: 733-735.

47. Uckan S, Dayangac E, Araz K. Erratum to 'Is permanent maxillary tooth removal without palatal injection possible?' Oral Surg Oral Med Oral Pathol Oral Radiol Endod 2007: 103: 580.

48. Fan S, Chen W L, Yang Z H, Huang Z O. Comparison of the efficiencies of permanent maxillary tooth removal performed with single buccal infiltration versus routine buccal and palatal injection. Oral Surg Oral Med Oral Pathol Oral Radiol Endod 2009; 107: 359-363.

49. Badcock M E, Gordon I, McCullough M J. A blinded randomized controlled trial comparing lignocaine and placebo administration to the palate for removal of maxillary third molars. Int J Oral Maxillofac Surg 2007: 36: 1177-1182.

50. Ozeç I, Tasdemir U, Gümüs C, Solak O. Is it possible to anesthetize palatal tissues with buccal $4 \%$ articaine injection? J Oral Maxillofac Surg 2010; 68: 1032-1037.

51. Katyal V. The efficacy and safety of articaine versus lignocaine in dental treatments: a metaanalysis. J Dent 2010; 38: 307-317.

52. Hargreaves K M, Keiser K. Local anesthetic failure in endodontics: mechanisms and management. Endod Topics 2002; 1: 26-39.

53. Madan G A, Madan S G, Madan A D. Failure of inferior alveolar nerve block: exploring the alternatives. J Am Dent Assoc 2002; 133: 843-846.

54. Potocnik I, Bajrović F. Failure of inferior alveolar nerve block in endodontics. Endod Dent Traumatol 1999; 15: 247-251.

55. Boronat López A, Peñarrocha Diago M. Failure of locoregional anesthesia in dental practice. Review of the literature. Med Oral Patol Oral Cir Bucal 2006; 11: E510-513

56. Wallace J, Michanowicz A, Mundell R, Wilson E. A pilot study of the clinical problem of regionally anesthetizing the pulp of an acutely inflamed mandibular molar. Oral Surg Oral Med Oral Pathol 1985; 59: 517-521.

57. Byers $M$, Taylor $P$, Khayat $B$, Kimberly C. Effects of injury and inflammation on pulpal and periapical nerves. J Endod 1990; 16: 78-84.

58. Rosenberg P A, Amin K G, Zibari Y, Lin L M Comparison of $4 \%$ articaine with 1:100,000 epinephrine and 2\% lidocaine with 1:100, 000 epinephrine when used as a supplemental anesthetic. J Endod 2007; 33: 403-405.

59. Sherman M G, Flax M, Namerow K, Murray P E. Anesthetic efficacy of the Gow-Gates injection and maxillary infiltration with articaine and lidocaine for irreversible pulpitis. J Endod 2008; 34: 656-659.

60. Srinivasan N, Kavitha M, Loganathan C S, Padmini G. Comparison of anesthetic efficacy of $4 \%$ articaine and 2\% lidocaine for maxillary buccal infiltration in patients with irreversible pulpitis. Oral Surg Oral Med Oral Pathol Oral Radiol Endod 2009; 107: 133-136

61. Nusstein J, Reader A, Beck F M. Anesthetic efficacy of different volumes of lidocaine with epinephrine for inferior alveolar nerve blocks. Gen Dent 2002; 50: $372-375$

62. Claffey E, Reader A, Nusstein J, Beck M, Weaver J. Anesthetic efficacy of articaine for inferior alveolar nerve blocks in patients with irreversible pulpitis. J Endod 2004: 30: 568-571.

63. Tortamano I P, Siviero M, Costa C G, Buscariolo I A, Armonia P L. A comparison of the anesthetic efficacy of articaine and lidocaine in patients with irreversible pulpitis. J Endod 2009; 35: 165-168.

64. Maniglia-Ferreira C, Almeida-Gomes F, CarvalhoSousa B et al. Clinical evaluation of the use of three anesthetics in endodontics. Acta Odontol Latinoam 2009; 22: 21-26.

65. Aggarwal V, Singla M, Kabi D. Comparative evaluation of anesthetic efficacy of Gow-Gates mandibular conduction anesthesia, Vazirani-Akinosi technique, buccal-plus-lingual infiltrations, and conventional inferior alveolar nerve anesthesia in patients with irreversible pulpitis. Oral Surg Oral Med Oral Pathol Oral Radiol Endod 2010; 109: 303-308.

66. Goldberg S, Reader A, Drum M, Nusstein J, Beck M. Comparison of the anesthetic efficacy of the conventional inferior alveolar, Gow-Gates, and Vazirani-Akinosi techniques. J Endod 2008; 34: 1306-1311.

67. Matthews R, Drum M, Reader A, Nusstein J, Beck M. Articaine for supplemental buccal mandibular infiltration anesthesia in patients with irreversible pulpitis when the inferior alveolar nerve block fails. J Endod 2009; 35: 343-346.

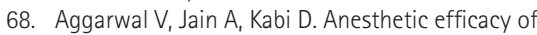
supplemental buccal and lingual infiltrations of articaine and lidocaine after an inferior alveolar nerve block in patients with irreversible pulpitis. $J$ Endod 2009; 35: 925-929.

69. Fan S, Chen W L, Pan C B et al. Anesthetic efficacy of inferior alveolar nerve block plus buccal infiltration or periodontal ligament injections with articaine in patients with irreversible pulpitis in the mandibular first molar. Oral Surg Oral Med Oral Pathol Oral Radiol Endod 2009; 108: e89-93.

70. Nusstein J, Claffey E, Reader A, Beck M, Weaver I. Anesthetic effectiveness of the supplemental intraligamentary injection, administered with a computer-controlled local anesthetic delivery system, in patients with irreversible pulpitis. J Endod 2005; 31: 354-358.

71. Bigby J, Reader A, Nusstein J, Beck M, Weaver J. Articaine for supplemental intraosseous anesthesia in patients with irreversible pulpitis. J Endod 2006; 32: 1044-1047.

72. Nusstein J, Reader A, Nist R, Beck M, Meyers W J. Anesthetic efficacy of the supplemental intraosseous injection of $2 \%$ lidocaine with 1:100,000 epinephrine in irreversible pulpitis. J Endod 1998; 24: 487-491.

73. Parente S A, Anderson R W, Herman W W, Kimbrough W F, Weller R N. Anesthetic efficacy of the supplemental intraosseous injection for teeth with irreversible pulpitis. J Endod 1998; 24: 826-828.

74. Nusstein J, Kennedy S, Reader A, Beck M, Weaver $J$. Anesthetic efficacy of the supplemental X-tip intraosseous injection in patients with irreversible pulpitis. J Endod 2003; 29: 724-728.

75. Jakobs W, Ladwig B, Cichon P, Ortel R, Kirch W. Serum levels of articaine $2 \%$ and $4 \%$ in children. Anesth Prog 1995; 42: 113-115.

76. Adewumi A, Hall M, Guelmann M, Riley J. The incidence of adverse reactions following 4\% septocaine (articaine) in children. Pediatr Dent 2008; 30: 424-428.

77. Septanest (4\% Articaine with 1:100,000 adrenaline) product insert, May 2004. Septodont Saint-Maur-des-Fossés Cedex, France.

78. Wright G Z, Weinberger S J, Friedman C S, Plotzke $O B$. Use of articaine local anesthesia in children under 4 years of age - a retrospective report. Anesth Prog 1989; 36: 268-271.

79. Brickhouse T H, Unkel J H, Webb M D, Best A M, Hollowell R L. Articaine use in children among dental practitioners. Pediatr Dent 2008; 30: 516-521.

80. Dudkiewicz A, Schwartz S, Laliberte R. Effectiveness of mandibular infiltration in children using the local anesthetic Ultracaine (articaine hydrochloride). J Can Dent Assoc 1987; 53: 29-31.

81. Wright $\mathrm{G} Z$, Weinberger $\mathrm{S} J$, Marti R, Plotzke 0. The effectiveness of infiltration anesthesia in the mandibular primary molar region. Pediatr Dent 1991; 13: 278-283.

82. Oulis C J, Vadiakas G P, Vasilopoulou A. The effectiveness of mandibular infiltration compared to mandibular block anesthesia in treating primary molars in children. Pediatr Dent 1996; 18: 301-305.

83. Malamed S F, Gagnon S, Leblanc D. A comparison between articaine $\mathrm{HCl}$ and lidocaine $\mathrm{HCl}$ in pediatric dental patients. Pediatr Dent 2000; 22: 307-311.

84. Ram D, Amir E. Comparison of articaine $4 \%$ and lidocaine $2 \%$ in paediatric dental patients. Int J Paediatr Dent 2006; 16: 252-256.

85. Sixou J L, Barbosa-Rogier M E. Efficacy of intraosseous injections of anesthetic in children and adolescents. Oral Surg Oral Med Oral Pathol Oral Radiol Endod 2008; 106: 173-178.

86. Subramaniam S, Tennant M. A concise review of the basic biology and pharmacology of local analgesia. Aust Dent J 2005; 50(4 Suppl 2): S23-30

87. Finder R L, Moore P A. Adverse drug reactions to 
local anesthesia. Dent Clin North Am 2002; 46: 747-757.

88. Malanin K, Kalimo K. Hypersensitivity to the local anesthetic articaine hydrochloride. Anesth Prog 1995; 42: 144-145.

89. Peñarrocha-Diago M, Sanchis-Bielsa J M Ophthalmologic complications after intraoral local anesthesia with articaine. Oral Surg Oral Med Oral Pathol Oral Radiol Endod 2000; 90: 21-24.

90. Koumoura F, Papageorgiou G. Diplopia as a complication of local anesthesia: a case report. Quintessence Int 2001; 32: 232-234.

91. Magliocca K R, Kessel N C, Cortright G W. Transient diplopia following maxillary local anesthetic injection. Oral Surg Oral Med Oral Pathol Oral Radiol Endod 2006; 101: 730-733.

92. Kocer B, Ergan S, Nazliel B. Isolated abducens nerve palsy following mandibular block articaine anesthesia, a first manifestation of multiple sclerosis: a case report. Quintessence Int 2009; 40: 251-256.

93. Torrente-Castells E, Gargallo-Albiol J, RodríguezBaeza A, Berini-Aytés L, Gay-Escoda C. Necrosis of the skin of the chin: a possible complication of inferior alveolar nerve block injection. J Am Dent Assoc 2008; 139: 1625-1630.

94. Petitpain N, Goffinet L, Cosserat F, Trechot P, Cuny J F. Recurrent fever, chills, and arthralgia with local anesthetics containing epinephrine-metabisulfite. J Clin Anesth 2008; 20: 154.

95. Haas D A, Lennon D. A 21 year retrospective study of reports of paresthesia following local anesthetic administration. J Can Dent Assoc 1995; 61: 319-330.

96. Hillerup $S$, Jensen R. Nerve injury caused by mandibular block analgesia. Int J Oral Maxillofac Surg 2006; 35: 437-443.
97. Gaffen A S, Haas D A. Retrospective review of voluntary reports of nonsurgical paresthesia in dentistry. J Can Dent Assoc 2009; 75: 579.

98. Garisto G A, Gaffen A S, Lawrence H P, Tenenbaum H C, Haas D A. Occurrence of paresthesia after dental local anesthetic administration in the United States. J Am Dent Assoc 2010; 141: 836-844.

99. Haas D A, Lennon D. A review of local anestheticinduced paresthesia in Ontario in 1994 (abstract 1834). J Dent Res 1996; 75(Spec Iss): 247.

100. Miller P A, Haas D A. Incidence of local anaesthetic induced neuropathies in Ontario from 1994-1998 (abstract 3869). J Dent Res 2000; 79(Spec Iss): 627

101. Pogrel M A, Bryan J, Regezi J. Nerve damage associated with inferior alveolar nerve blocks. J Am Dent Assoc 1995; 126: 1150-1155.

102. Pogrel M A, Thamby S. Permanent nerve involvement resulting from inferior alveolar nerve blocks. J Am Dent Assoc 2000; 131: 901-907.

103. Pogrel M A. Permanent nerve damage from inferior alveolar nerve blocks - an update to include articaine. J Calif Dent Assoc 2007; 35: 271-273.

104. Gow-Gates G A. Mandibular conduction anesthesia: a new technique using extraoral landmarks. Oral Surg Oral Med Oral Pathol 1973; 36: 321-328.

105. Pogrel M A, Schmidt B L, Sambajon V, Jordan R C Lingual nerve damage due to inferior alveolar nerve blocks: a possible explanation. J Am Dent Assoc 2003; 134: 195-199.

106. Krafft T C, Hickel R. Clinical investigation into the incidence of direct damage to the lingual nerve caused by local anaesthesia. J Craniomaxillofac Surg 1994; 22: 294-296.
107. Harn S D, Durham T M. Incidence of lingual nerve trauma and postinjection complications in conventional mandibular block anesthesia. J Am Dent Assoc 1990; 121: 519-523.

108. Bernsen P L. Peripheral facial nerve paralysis after local upper dental anaesthesia. Eur Neurol 1993; 33: $90-91$.

109. Nusstein J, Burns Y, Reader A, Beck M, Weaver $J$ Injection pain and postinjection pain of the palatal-anterior superior alveolar injection, administered with the Wand Plus system, comparing 2\% lidocaine with 1:100,000 epinephrine to $3 \%$ mepivacaine. Oral Surg Oral Med Oral Pathol Oral Radiol Endod 2004. 97: 164-172.

110. Haas D A. Articaine and paresthesia: epidemiological studies. J Am Coll Dent 2006; 73: 5-10.

111. Cornelius $C P$, Roser $M$, Wietholter $H$, Wolburg $H$. Nerve injection injuries due to local anaesthetics. Experimental work. J Cranio Maxillofac Surg 2000; 28(Suppl 3): 134-135.

112. Malamed S F. Nerve injury caused by mandibular block analgesia. Int J Oral Maxillofac Surg 2006: 35: 876-877, author reply 878 .

113. Malamed S F. Articaine versus lidocaine: the author responds. J Calif Dent Assoc 2007; 35: 383-385.

114. Missika P, Khoury G. Paresthesia and local infiltration or block anesthesia. L'Information Dentaire 2005; 87: 2731-2736.

115. Shekelle P G, Woolf S H, Eccles M, Grimshaw J. Clinical guidelines: developing guidelines. $B M J$ 1999; 318: 593-596.

116. Sathorn C, Parashos P. Questions and answers in evidence-based patient care. Br Dent J 2007 203: 309-319. 